Original Article

\title{
Oral cancer awareness in rural Karnataka - are they aware?
}

\author{
Gopinath Thilak P.S. ${ }^{1}$, Renita D'leema ${ }^{2} \&$ Vinayak Kamath ${ }^{3}$ \\ ${ }^{1}$ Lecturer, Department of Oral \& M axillofacial Surgery, ${ }^{2}$ Intern, ${ }^{3}$ Lecturer, Department of Public Health Dentistry, \\ A.B. Shetty M emorial Institute of Dental Sciences, Nitte University, M angalore, Karnataka, India.

\section{Correspondence \\ Renita D'leema} \\ Intern, A.B. Shetty M emorial Institute of Dental Sciences, Nitte University, M angalore, Karnataka, India. \\ Mobile : +91 8951738331 E-mail : renitadleema@yahoo.com
}

\begin{abstract}
The statistical data of cancer, globally, shows that India has one of the highest incidence rates of oral cancer worldwide. Early detection is extremely important as it results in lower morbidity and death rates. The present study was undertaken to assess awareness of oral cancer and knowledge of its early signs and riskfactors in the general public of rural Karnataka (India). It was al so intended to educate the rural population for early detection by increasing their ability to recognize signs and risk factors. A systematic questionnaire was formatted related to oral cancer and cancer patients. A total of 267 people were randomly selected and questionnaires were distributed to 3 different rural areas of Dakshina Kannada district (Karnataka). The results were obtained and the level of oral cancer awareness in the rural population was studied.
\end{abstract}

Keywords: Oral cancer, Awareness, Rural Karnataka, Tobacco consumption

\section{Introduction}

Oral cancer is one of the lethal diseases persisting in India and most of the time occurs due to improper life style and adverse habits. Oral cancer accounts for approximately 2 , 00,000 deaths annually worldwide and around 46,000 deaths occurring in India ${ }^{1}$.There is a significant difference in the incidence of oral cancer in different regions of the world.Oral cancers, with its widely variable rate of occurrence, has one of the highest incidences in India constituting around $12 \%$ of all cancers in men and $8 \%$ of all cancers among women ${ }^{2}$.Despite recent advances in the detection and treatment of cancer, visual accessibility of the oral mucosa and the scientific knowledge on cancer risk factors, oral cancer carries a low survival rate (nearly 50\%). Earlier diagnosis greatly increases the patient's chances of survival as the mouth is very accessible for a clinical or self-

\begin{tabular}{|c|}
\hline Access this article online \\
\hline Quick Response Code \\
\hline
\end{tabular}

examination. However, oral cancer is still frequently diagnosed in advanced stages. One of the main reasons may be the lack of information about the causes and knowledge of signs and symptoms of oral cancer among the population. M oreover, most of the oral cancers are preventable if people know which risk factors they must control or eliminate ${ }^{3}$. In rural India there are majority of the people, still having minimal knowledge regarding oral cancer and its causes marking a high percentage when compared to the urban. The purpose of this study was to evaluate the awareness and access the knowledge in the rural public regarding oral cancer with the help of a questionnaire and to educate them. The study was done in rural areas of Dakshina Kannada district in Karnataka, namely, Thalipady, Hejmadikodi and M undkur.

\section{Materials and Methods}

This was a descriptive study carried out in the month of October, 2014. A total of 267 people gave their consent and participated in this survey, which included patients who came seeking dental treatment at the rural centres of Nitte University at Thalipady, Hejmadikodi and Mundkur and also the people living in and around the mentioned areas. $A$ questionnaire based survey was carried out which contained 11 questions regarding oral cancer and peoples approach towardsa patient (Fig: 1). 
The age group of the participants was $12-80$ years. The study included healthy individuals and people with oral habits without any precancerous oral changes who had come seeking dental treatment. Excluded from the study were those with precancerous conditions or lesions, patients suffering from oral cancer and those who were not willing to participate. The data was analysed and the statistics were calculated and the level of cancer awareness was studied.

\section{Results}

The study population consisted of $54.3 \%$ females and $45.7 \%$ males with an average age of 34 years (range 12-80 years)
The questionnaire consisted of relevant questions and was pre-tested and necessary alterations were done beginning with the introductory questions to evaluate the basic knowledge about oral cancer followed with questions related to their experience with oral cancer patients and in addition regarding people they know suffering from oral cancer as well as about the knowledge of treatment of oral cancer. The duly filled questionnaire was collected and was evaluated by the authors. Depending on the patient's knowledge based on the answers, individuals were educated regarding oral cancer and the patient management. The results of the survey are illustrated below. (Table: 1 )

Table 1: List of Questions with their Results in percentage.

\begin{tabular}{|c|c|c|c|}
\hline \multirow[t]{2}{*}{1} & \multirow[t]{2}{*}{ Have you heard about oral cancer? } & Yes & $232(86.9 \%)$ \\
\hline & & No & $35(13.1 \%)$ \\
\hline 2 & \multirow[t]{6}{*}{ What do you think is the cause of oral cancer? } & $\begin{array}{c}\text { Smoking, tobacco } \\
\text { chewing and spicy food }\end{array}$ & $245(91.8 \%)$ \\
\hline & & Hereditary & $13(4.9 \%)$ \\
\hline & & Curse & 0 \\
\hline & & Sexual spread & $1(0.4 \%)$ \\
\hline & & Blood transfusion & $1(0.4 \%)$ \\
\hline & & Others & $7(2.6 \%)$ \\
\hline 3 & \multirow{3}{*}{$\begin{array}{l}\text { Do you think oral cancer spreads from person to person } \\
\text { through touch or speaking? }\end{array}$} & Yes & $9(3.4 \%)$ \\
\hline & & No & $211(79.0 \%)$ \\
\hline & & Don't Know & $47(17.6 \%)$ \\
\hline \multirow[t]{3}{*}{4} & \multirow{3}{*}{$\begin{array}{l}\text { Is it true that sharing clothes and utensils with a cancer } \\
\text { patient cause spread of the disease? }\end{array}$} & Yes & $18(6.7)$ \\
\hline & & No & $202(75.7)$ \\
\hline & & Don't Know & $47(17.6)$ \\
\hline \multirow[t]{4}{*}{5} & \multirow[t]{4}{*}{ Do you think oral cancer is mainly seen in AIDS patients? } & Yes of course & $9(3.4 \%)$ \\
\hline & & No & $128(47.9 \%)$ \\
\hline & & Maybe & $90(33.7 \%)$ \\
\hline & & Don't know & $40(15.0 \%)$ \\
\hline \multirow[t]{2}{*}{6} & \multirow[t]{2}{*}{ Have you come across anyone suffering from oral cancer? } & Yes & $63(23.6 \%)$ \\
\hline & & No & $204(76.4 \%)$ \\
\hline \multirow[t]{3}{*}{7} & \multirow[t]{3}{*}{ If yes, what was your reaction when you saw him/her first? } & Got scared & $79(34.6 \%)$ \\
\hline & & Behaved normal & $136(59.6 \%)$ \\
\hline & & Tried to avoid & $13(5.7 \%)$ \\
\hline \multirow[t]{2}{*}{8} & \multirow{2}{*}{$\begin{array}{l}\text { Has any of your family members died or suffering } \\
\text { from oral cancer? }\end{array}$} & Yes & $33(12.4 \%)$ \\
\hline & & No & $234(87.6 \%)$ \\
\hline \multirow[t]{3}{*}{9} & \multirow[t]{3}{*}{ Do you think oral cancer is curable? } & Yes & $93(34.8 \%)$ \\
\hline & & No & $54(20.2 \%)$ \\
\hline & & Don't Know & $120(44.9 \%)$ \\
\hline \multirow[t]{3}{*}{10} & \multirow{3}{*}{$\begin{array}{l}\text { Being the general public, what should we do to help } \\
\text { patients suffering from cancer? }\end{array}$} & Get required treatment & $152(56.9 \%)$ \\
\hline & & Support them and get friendly & $97(36.3 \%)$ \\
\hline & & Don't ask me & $18(6.7 \%)$ \\
\hline \multirow[t]{2}{*}{11} & \multirow{2}{*}{$\begin{array}{l}\text { Do you think this survey has created awareness in you } \\
\text { regarding oral cancer? }\end{array}$} & Yes & $226(84.6 \%)$ \\
\hline & & No & $41(15.4 \%)$ \\
\hline
\end{tabular}


Fig. 1 : Questionnaires designed for the participants including the patients consent.

\section{A.B. SHETTY MEM ORIAL INSTITUTE OF DENTAL SCIENCES}

SURVEY ON ORAL CANCER AWARENESS IN RURAL KARNATAKA

1) Have you heard about oral cancer?
a) Yes
b) No

2) What do you think is the cause of oral cancer?
a) Smoking tobacco, chewing \& spicy food
b) Hereditary
c) Curse
d) Sexual spread
e) Blood transfusion
f) Others

3) Do you think oral cancer spreads from person to person through touch or speaking?
a) Yes
b) No
c) Don't Know

4) It is true that sharing clothes \& utensils with a cancer patient cause to spread of the disease?
a) Yes
b) No
c) Don't Know

5) Do you think oral cancer is mainly seen in the AIDS Patients?
a) Yes of course
b) No
c) May be
d) Don't know

6) Have you come across anyone suffering from oral cancer?
a) Yes
b) No

7) If yes, what was your reaction when you saw him/her first?
a) Got scared
b) behaved normal
c) Tried to avoid

8) Has any of your family members died or suffering from oral cancer?
a) Yes
b) No

9) Do you think oral cancer is curable?
a)Yes
b) No
c) Don't know

10) Being the general public. What should we do to help patients suffering from cancer? a)Get required treatment b)Support them \& get friendly

c) Don't ask me

11) Do you think this survey has created awareness in you regarding oral cancer?
a) Yes
b) No

\section{INFORMED CONSENT}

I give my consent for participation in the survey on oral cancer. I have answered the above questions to the best of my knowledge \& out of my own will.

$\begin{array}{lll}\text { NAME } & \text { AGE : } \\ \text { SEX } & : & \text { ADDRESS : }\end{array}$

SIGNATURE :

\section{Discussion}

Oral cancer is one of the easily diagnosed disease when compared to the other cancers developing in the body, yet the awareness among the general public specially the rural population is minimal leading to the presentation of oral cancer in their terminal stages.

There are many surveys undertaken in the private and government dental and medical colleges ${ }^{4,5}$ to evaluate the patient's knowledge on specific problems but very minimal surveys have been taken place in the rural areas which needs attention. Prasad L.K ${ }^{6}$ in his study explains that physical, psychological, social and economic state of an individual, stance a massive constrain in reaching out to the affected strata. Increasing number of oral cancer patients belong to weaker socioeconomic section with lack of awareness and having misconceptions.
According to the present study majority of the group seemed to be aware regarding oral cancer and cancer patients, withholding a few number of subjects deprived of basic knowledge. $13.1 \%$ of the people had never heard about oral cancer in the authors study group, $4.9 \%$ of the people said the cause of oral cancer was hereditary while a negligible number said it was sexual spread and blood transfusion. On being asked if oral cancer spreads by sharing clothes and utensils a same number (17.6\%) said they do not know while a small but significant $6.7 \%$ said yes (Table:1). N.B.Ramachandra ${ }^{7}$ in his paper explains that apart from chewing habits, illiteracy is one of the major causes for rise in oral cancer incidences.

Authors had put forward a question regarding prevalence of oral cancer in AIDS patients, $33.7 \%$ of the participants were confused while, on the other hand $15 \%$ said they did 
not know, $3.4 \%$ said yes it is mainly seen in AIDS patients (Table: 1 ) . SDas et al ${ }^{8}$ in his article stresses on the increase in efforts to expand the resources for health education and increase awareness of cancer prevention to the people and health care providers with an unprecedented level of cooperation among international agencies, government and nongovernmental organizations, international foundations, healthcare system and local institutions.

The authors wanted to evaluate the social stigma towards patients suffering from oral cancer. $23.6 \%$ of the population has come across someone suffering from oral cancer, but still there seemed a lack of awareness among the population. When asked on how they reacted when they came across a patient suffering of oral cancer, $34.6 \%$ said they got scared while $5.7 \%$ said they tried to avoid the patient. This large number shows how the rural population is hesitant and reluctant to even come across a patient. Another question asked was whether any family member has died or is suffering from oral cancer, $12.4 \%$ answered saying yes (Table: 1). This shows that there have been deaths of patients or people presently suffering from cancer in and around the surveyed area. Argerakis GP ${ }^{9}$ in his article related to psychosocial considerations of the posttreatment of head and neck cancer patients, explains that because of serious functional disabilities, such as speech impairment and chewing-swallowing difficulties, along with facial disfigurement, these individuals suffer the most problems of any type of cancer patient. Without skilled rehabilitation intervention, their emotional, social, economic, and physical well-being will be greatly impacted, perhaps for life. According to him despite better treatment methods today, despite higher survival rates, we have not sufficiently changed our attitudes toward cancer rehabilitation. The same social stigma has stubbornly lingered, together with the fears of morbidity, uncertainty, and unpredictability. To help the patient recover old skills and pleasures, we must overcome these obstacles and make them feel like a useful human being without any stigma attached, without undue fears and pressures but with a sense of being needed and wanted, that is what life is allabout.
Regarding the question whether oral cancer was curable or no, a large number, $44.9 \%$, said they did not know while $20.2 \%$ said no, it is not curable (Table: 1 ). This put light on a serious issue that the rural population is still unaware that oral cancer is completely curable if detected early and treated immediately. High mortality due to cancer is largely related to delay in diagnosis or not seeking advice regarding avenues of treatment and prevention. A Ariyawardana et al ${ }^{10}$ survey revealed that $5.9 \%$ of the population was not aware of the possibilities of treatment and $5.4 \%$ believed that there is no treatment available for oral cancer. This may lead to a "loss of hope" type of situation resulting in a delay in seeking treatment or the patient may not seek treatment at all.

We did conclude that the rural population was sensitive towards a patient when $36.3 \%$ said that being the general public we must support them and get friendly while $56.9 \%$ said we should help them get required treatment (Table:1). This shows the helping nature of the population and their concern for everyone. Before subjecting to survey, the participants were instructed not to fill the last question which was regarding awareness created in them after answering the questionnaire. The authors evaluated the participant's knowledge depending on the filled data and specific discussions related to the questions were undertaken. Following which they were instructed to fill the last question. It gave the authors a sense of satisfaction when $84.6 \%$ (Table: 1 ) of the people said our survey created awareness among them about oral cancer and thus, we helped them to help themselves and others.

Covering the above data, the root to solve such issues is awareness in form of education to the general public by every health personnel. Studies conducted by Rahman B et $\mathrm{al}^{11}$ and Carter $L \mathrm{M}^{12}$, regarding oral cancer awareness among dental and medical students highlighted the facts that there was a apparent lack of knowledge of oral cancer risk factors among students, that may later result in a deficiency in integrating optimal oral cancer diagnostic procedures in their practices hence need of improved education of undergraduate medical and dental students 
regarding oral cancer. Patients with oral lesions often present to their general medical or dental practitioner and therefore the role of general practitioners in prevention and detection of oral cancer is becoming ever more important ${ }^{13}$.

The study regarding oral cancer are enormous, awareness programs are initiated in various schools and colleges for the students and general public in the form of treatment camps, oral screening camps, cancer awareness lectures and questionnaires. The results of such studies have helped in providing minimal knowledge among the public about such irreversible disease. According to the authors, presentations regarding oral cancer have to be divided depending on different groups like for the school students, for the general public, and for the cancer patients. According to the authors such divisions helps in addressing specific problems among the different groups and providing a better education and health support. Questionnaire regarding various health aspects specially oral cancer should be formatted, distributed and knowledge evaluated in every treatment and screening camp conducted by the medical or dental colleges or associations, the patients or public should be identified with the least scores and should be educated on the same day in the form of group discussion or presentations which will help serve the defined purpose of a camp. The authors of the present study formatted the questionnaire for the general public in the rural districts of Karnataka in order to evaluate their knowledge and to educate them. According to the authors the prime duty of the health providers is not only to provide better treatment but to educate the patient after looking at the pros and cons from the patient feedback.

\section{Conclusion}

India constitutes more than $80 \%$ of the population from the villages and is not only socially and economically deprived but also do not get medical facilities compared to small towns and cities. The ultimate goal of all programs is to decrease the incidence of disease and improve the effectiveness of treatment. They should be educated and positively encouraged to participate in educational programs like oral cancer prevention with the hope of minimizing the incidence of this dreadful disease. Community health workers, dental surgeons and allied medical professionals should take the responsibility to organize low-cost educational programmes that are designed and launched to reach less privileged groups in our society.

\section{Acknowledgment}

The authors would like to sincerely thank the staff of the Nitte University Rural Centres for their support and cooperation and also the Public Health Department of A.B. Shetty M emorial Institute of Dental Sciences.

\section{References}

1. Jemal A, Siegel R, XuJ, Ward E. Cancer statistics. CA: Cancer J Clin 2010; 60:277-300.

2. Mamta Agrawal, SushmaPandey, Shikha Jain, ShipraMaitin. Oral Cancer Awareness of the General Public in Gorakhpur City. Asian Pacific J ournal of Cancer Prevention 2012; 13: 5195-5199.

3. Luis Silva, Monteiro, Filomena Salazar, Julio Pacheco, SamanWarnakulaSuriya. Oral Cancer Awareness and Knowledge in the City of Valongo, Portugal. International Journal of Dentistry 2012; Article ID 376838, 8 pages.

4. Srikanth Reddy B, Doshi D, Padma Reddy M , Kulkarni S, Gaffar A, Ram Reddy V. Oral cancer awareness and knowledge among dental patients in South India.J Craniomaxillofac Surg. 2012;40(6):521-4.

5. Hassona Y, Scully C, Abu Ghosh M, Khoury Z, Jarrar S, Sawair F. M outh cancer awareness and beliefs among dental patients. Int Dent J. 2015; Feb;65(1):15-21.

6. Prasad LK. Burden of oral cancer: An Indian scenario. J OrofacSci 2014; 6:77-79.

7. NaikBalachandra Ramachandra. The Hierarchy of oral cancer in India.

International Journal of head and neck surgery 2012; 3(3): 143-146.

8. S Das, KC Patro. Cancer care in the rural areas of India: A firsthand experience of a clinical oncologist and review of literature. Journal of Cancer Research and Therapeutics 2010; 6:299-303

9. Argerakis G.P. Psychosocial considerations of the post-treatment of head and neck cancer patients. Dental Clinics of North America 1990; 34(2):285-305.

10. AAriyawardana, $\mathrm{N}$ Vithanaarachchi. Awareness of Oral Cancer and Precancer among Patients Attending a Hospital in Sri Lanka. Asian Pacific Cancer 2005; 6: 58-61.

11. Rahman B, Hawas N, Rahman M M, Rabah AF, Al Kawas S. Assessing dental students knowledge of oral cancer in the United Arab Emirates. Int. Dent. J. 2013 Apr; 63(2):80-4.

12. Carter LM, Ogden GR. Oral cancer awareness of undergraduate medical and dental students. BM CM ed Educ. 2007 Nov 15; 7:44.

13. Carter LM, Ogden GR. Oral cancer awareness of general medical and general dental practitioners. Br Dent J. 2007 Sep 8;203(5):10:248-9 